\title{
VARIÁVEIS SOCIOECONÔMICAS E GASTOS PÚBLICOS AMBIENTAIS DOS MUNICÍPIOS BRASILEIROS: UMA ANÁLISE NO PERÍODO DE 2005 - 2015
}

\author{
Data de submissão: 06/04/2018 \\ Aceite: 29/09/2018 \\ Paulo Vinícius de Miranda Pereira ${ }^{1}$ \\ Leonardo Francisco Figueiredo Neto $^{2}$
}

\section{RESUMO}

O objetivo deste artigo consistiu em analisar a relação entre algumas variáveis socioeconômicas e os gastos públicos ambientais dos municípios brasileiros com mais de 100 mil habitantes, no período 2005 a 2015. Para tanto, utilizou-se a regressão linear múltipla com os dados dos gastos públicos ambientais e os dados socioeconômicos dos 303 selecionados. Além do Gasto Ambiental, as variáveis analisadas foram: Despesas totais, Renda per capita, Produto Interno Bruto (PIB), Despesa per capita, Desempenho Verde das Despesas, Desempenho Ambiental do PIB, Gasto Ambiental por área territorial e Gasto Ambiental por Habitante. A pesquisa permitiu observar que as questões socioeconômicas parecem determinar em maior grau os gastos ambientais municipais, uma vez que a regressão confirmou que 08 variáveis foram significativas (Desempenho Ambiental do PIB não foi significativo). Os resultados indicaram ainda que essas variáveis socioeconômicas sugerem um poder explicativo de aproximadamente $85 \%$ sobre os gastos ambientais realizados pelos municípios brasileiros no período estudado. Este estudo é uma contribuição adicional relacionada ao tema, apresentando uma análise quantitativa dos gastos ambientais no contexto municipal, podendo ser uma ferramenta importante aos gestores públicos que auxilie no debate, planejamento e execução da política pública voltada ao meio ambiente.

Palavras-Chave: Gestão ambiental. Política Pública Ambiental. Gestão Pública Municipal

\footnotetext{
1 Possui graduação em Agronomia pela Universidade do Estado de Mato Grosso, UNEMAT, mestrado em Administração pela Universidade Federal de Mato Grosso do Sul, UFMS e doutorado em andamento em Agronegócios pela Universidade Federal do Rio Grande do Sul, UFRGS.

E-mail: paulomiranda@unemat.br

2 Possui graduação em Agronomia pela Universidade Federal do Espírito Santo, UFES, mestrado em Ciências (Economia Aplicada) pela Universidade de São Paulo, USP e doutorado em Engenharia (Engenharia de Produção) pela USP. Campo Grande-MS. Brasil E-mail: Iffneto@gmail.com
} 


\section{INTRODUÇÃO}

Diante do crescimento econômico mundial, sustentado por um processo de globalização, muito tem se debatido a respeito da finitude dos recursos naturais. O Estado, por meio de sua agenda política, sujeito à perspectiva do crescimento econômico, expandiu suas políticas públicas, balizando-se no consumo de bens e serviços e geração de emprego e renda.

A partir desse momento, despertou-se na Administração Pública o pensamento de investir em métodos para a prevenção e recuperação ambiental. Neste sentido, a questão ambiental tornou-se o cerne das discussões, passando a ser destaque nos desígnios da atuação estatal frente ao desenvolvimento de políticas públicas orientadas para a sustentabilidade.

Para Pacheco et al. (2015), um meio ambiente ecologicamente equilibrado é um direito a ser garantido pelo Estado, e, que as ações de gestão ambiental devem ser previstas e expostas, de forma transparente, no orçamento público, viabilizando o controle social.

Essas ações, segundo Barbieri (2011), são chamadas de Políticas Públicas Ambientais, que são "[...] um conjunto de objetivos, diretrizes e instrumentos de ação que o poder público dispõe para evitar novos problemas ambientais, bem como para eliminar ou minimizar os existentes" (BARBIERI, 2011, p. 71). Conforme Guandalini, Borinelli e Godoy (2013), com a inserção das políticas públicas ambientais os governos têm criado órgãos, leis e programas ambientais, alocando recursos orçamentários para tal fim.

Com a criação da Lei Federal no 6.938 de 1981, foi iniciada a institucionalização da gestão ambiental no Brasil, estabelecendo a chamada Política Nacional de Meio Ambiente (PNMA) e a constituição do Sistema Nacional de Meio Ambiente (SISNAMA), tornando legitima a descentralização da gestão ambiental, sendo composto por todos os entes federativos e funções instituídas pelo poder público, de modo a articular as diferentes esferas do poder, buscando facilitar a execução das respectivas competências (SCARDUA, 2003).

Em geral, pesquisas envolvendo a temática do gasto ambiental começaram a ser realizadas a partir da década de 1990 (GUIMARÃES, CARNEIRO, DOWELL, 1992; IBGE, 2001; YOUNG, RONCISVALLE, 2002), oportunizando razoáveis entendimentos sobre as políticas públicas ambientais, uma vez que estudos nesse sentido podem coadjuvar no entendimento do contexto político, da sustentabilidade e do processo orçamentário. Com a padronização e transparência das informações públicas, ocorridas no início do ano 2000 , foi possível a ampliação nas possibilidades de análise e avaliação das políticas públicas ambientais (BORINELLI et al., 2011; TRIDAPALLI et al., 2011; YOUNG, GELUDA, LEMOS, 2006; GUANDALINI, BORINELLI, GODOY, 2013; DANTAS et al., 2014).

\subsection{Objetivos e justificativa}

Recentemente, surgiram estudos na área de gestão pública ambiental utilizando técnicas estatísticas multivariadas para analisar a relação do gasto ambiental com características da região estudada (BUENO, 2013; GUANDALINI, 2016). De acordo Bueno (2013), técnicas de análise multivariada podem proporcionar uma análise mais detalhada sobre os fatores que interferem no comportamento dos gastos ambientais. Sendo assim, pergunta-se: existem fatores que influenciam os gastos públicos ambientais dos municípios brasileiros?

Nesse contexto, busca-se, nesta pesquisa, cooperar para o debate sobre as perspectivas e a pertinência de estudos com relação ao gasto público ambiental, acrescentando que estudos mais abrangentes sobre os gastos públicos ambientais no âmbito nacional são escassos. 
Dessa forma, o estudo visa analisar os municípios brasileiros com população maior que 100 mil habitantes. Tendo em vista que a padronização do registro dos gastos públicos ambientais ocorreu somente a partir dos anos 2000 (Portaria n 42 de 1999 do Ministério de Orçamento e Gestão), e que o processo de criação de municípios no Brasil é um processo histórico e frequente, faz-se necessário realizar um estudo, principalmente nos maiores municípios brasileiros (população acima de 100 mil), pois são municípios com criação anterior à da Portaria, ou seja, possuem dados de toda a série temporal, e, são áreas munícipes em que mais da metade $(56,1 \%)$ da população habita (IBGE, 2016).

Segundo dados do Instituto Brasileiro de Geografia e Estatística - IBGE (2016), a distribuição da população brasileira em seus 5.570 municípios mostra uma alta concentração em grandes centros urbanos, os 41 municípios com mais de 500 mil habitantes reúnem 29,9\% da população do Brasil (61,2 miIhões de habitantes) e mais da metade da população brasileira (56,1\% ou 114,6 milhões de habitantes) vive em apenas 5,5\% dos municípios (304 municípios), que são aqueles com mais de 100 mil habitantes.

Diante do exposto, este estudo tem por objetivo analisar a relação entre algumas variáveis socioeconômicas selecionadas e os gastos públicos ambientais dos municípios brasileiros. Especificamente, foi pesquisada essa relação nos municípios com população igual ou superior a 100 mil habitantes, no período 2005 a 2015.

\section{REVISÃO DE LITERATURA}

O estudo dos gastos públicos correlaciona-se com a análise da intervenção do Estado na economia, sobretudo, por meio da obtenção de recursos provenientes da sociedade e a sua realocação na forma de bens e serviços ofertados ao público, para supressão das falhas de mercado (SILVA et al., 2007).

Gastos públicos são despesas governamentais realizadas legalmente sob a forma de custeio, investimentos, transferências e inversões financeiras para cumprir as funções do governo (GIAMBIAGI; ALÉM, 2000).

Para Matias-Pereira (2010), nos países em desenvolvimento, em que se busca atingir níveis ideais de equidade social, ampliam-se as atribuições econômicas governamentais, que são concretizadas por meio da ação estatal nas receitas e despesas públicas, sendo o gasto público seu principal meio de intervenção. Mediante sua utilização, o governo define suas prioridades em relação à prestação de serviços públicos básicos e aos investimentos a serem realizados.

De acordo Carneiro; Moura e Neto (2013), as dotações orçamentárias do setor público possuem várias classificações e uma delas é a despesa por Função. Por Função de despesa, conforme a Portaria no. 42/99, deve-se entender o maior nível de agregação das diversas áreas de despesa que competem ao setor público. Ainda segundo esta norma, a subfunção representa uma partição da função. As subfunções da Função 18 - Gestão Ambiental são: i) preservação e conservação ambiental (541); ii) controle ambiental (542); iii) recuperação de áreas degradadas (543); iv) recursos hídricos (544); e, v) meteorologia (545).

Importa esclarecer que os gastos públicos ambientais refletem a infraestrutura para a gestão ambiental, as demandas políticas e a produção econômica de uma determinada região, o que torna sua análise essencialmente complexa, uma vez que envolvem relações econômicas entre o mercado e o ente público, as quais nem sempre são fáceis de mensurar (CARNEIRO, 2008).

Assim, os gastos públicos ambientais estão conexos com a preservação e recuperação ambiental, sendo que tais gastos do setor público são realizados por órgãos encarregados pelo controle ambiental, pelos programas de reflorestamento, monitoramento de áreas degradadas, programas de prevenção ambiental, remoção do lixo em áreas de proteção e manutenção das reservas ambientais (TRIDAPALLI et al., 2011). 
Uma das primeiras pesquisas a analisar os fatores associados aos gastos ambientais foi realizada por Sacco e Leduc (1969), cujo objetivo foi a verificação da relação entre fatores socioeconômicos e a estrutura política ambiental. Esses autores identificaram um indício de que o desenvolvimento econômico (características socioeconômicas) explicava mais a variação da política (ambiental) do que a estrutura política. Identificaram ainda que a densidade populacional, aquecimento, transporte de massa, bem como a coleta de lixo influenciava os gastos ambientais.

Outro estudo pioneiro, que teve como objeto de análise os gastos públicos ambientais foi realizado por Stanton e Whitehead (1994), que avaliaram a influência de grupos de interesse sobre os gastos com qualidade do ar e da água nos estados norte-americanos nas décadas de 1970 e 1980. Uma das conclusões apresentadas foi evidenciar que gasto ambiental estatal tem uma relação inversa com influência ou de grupos organizados (lobbies) em questões relativas ao meio ambiente.

Lemos, Young e Geluda (2006) fizeram um estudo sobre os gastos ambientais brasileiros, no período de 2000 a 2005, para a União, Estados e Municípios, no qual usou a despesa total e o gasto ambiental corrigidos para o último ano da pesquisa.

Dutra, Oliveira e Prado (2006), utilizando ainda os gastos totais e as receitas primárias da União, analisaram os gastos do Ministério do Meio Ambiente (MMA), no período de 2000 a 2005. Em ambos os estudos se concluiu que os gastos ambientais não eram prioridade no contexto orçamentário. Os autores enfatizam que parte significativa dos recursos autorizados é alocada para a reserva de contingência (em algumas situações para o pagamento de serviços da dívida), e, concomitantemente, parte das despesas autorizadas não será aplicada por dificuldades de execução orçamentária.

Carneiro (2008), em seu estudo sobre os gastos públicos ambientais brasileiros, mais especificamente do MMA, constatou que o orçamento do referido Ministério é muito pequeno quando comparado com outros ministérios (aproximadamente $0,15 \%$ do total das despesas) e que não há grandes oscilações em seus gastos. $O$ autor salientou que a função gestão ambiental ficou com $0,31 \%$ da despesa liquidada federal no período.

Tridapalli et al. (2011) realizaram uma investigação bibliográfica e documental em estudos, a nível internacional e nacional. No Brasil, as pesquisas sobre gastos ambientais tiveram início a partir dos anos de 1990 com ênfase na análise do governo federal e as despesas totais, por função e por subfunções da gestão ambiental, e o uso dos indicadores de valores absoluto e relativo por função, proporção entre despesa orçada e liquidada. Por outro lado, em estudos internacionais é enfatizada a correlação entre indicadores econômicos e gastos ambientais.

Utilizando dados de quatros países, Magnani (1999) estudou como o crescimento na renda e a distribuição da renda afetam os gastos públicos com pesquisa e desenvolvimento na área ambiental em países com renda alta, utilizando dados de 1980 a 1991. Foi constatada uma correlação positiva com investimentos na área ambiental e maior renda per capita.

Bacot e Dawes (1997); Daley e Garand (2005) classificaram os determinantes dos gastos ambientais em: Socioeconômicos, incluindo as características demográficas; estrutural/Administrativa, incluindo as instituições públicas que estão ligadas as questões ambientais; e política, que inclui a existência de grupos de interesse para os negócios ambientais, isto é, diversos índices e/ou medidas ambientais.

$\mathrm{Na}$ tabela 1 são apresentadas as principais variáveis utilizadas na quais os autores classificaram como socioeconômicas. Observa-se que nos trabalhos, os autores aplicaram os gastos públicos em meio ambiente como variável dependente, bem como diversas variáveis explicativas para tentar depreender os determinantes nas ações governamentais ao enfrentar os problemas ambientais. Os autores recorreram a técnicas inferenciais, entre elas, a regressão múltipla (STANTON, WHITEHEAD, 1994; BACOT, DAVES, 1997; NEWMARK, WITKO, 2007; KONISKY, WOODS, 2012). 
Na pesquisa realizada por Stanton e Whitehead (1994), para os gastos com a qualidade da água, os resultados mostraram que os grupos de pressão ambiental e a renda per capita se evidenciaram significativos. Para eles, o aumento na renda per capita provavelmente leva ao aumento no intento dos gastos para a conservação do meio ambiente, ou seja, quanto maior a renda per capita da sociedade, tende-se a uma maior a preocupação com a temática ambiental.

Tabela 1 - Principais variáveis socioeconômicas utilizadas em estudos sobre gastos ambientais.

\begin{tabular}{cl}
\hline \multicolumn{1}{c}{ Variáveis } & \multicolumn{1}{c}{ Autores } \\
\hline Despesa Geral & Lombard (1993); Sacco, Leduc (1969); Bueno (2013); Guandalini (2016) \\
& Sacco,Leduc (1969), Stanton, Whitehead (1994), Lombard, 1993; \\
Renda per capita & Newmark, Witko, (2007); Konisky, Woods (2012); Hays, Esler, Hays \\
& (1996); Daley, Garand, (2005); Bueno (2013) \\
& Sacco, Leduc (1969); Stanton, Whitehead (1994); Lombard (1993); \\
& Magnani (2000); Newmark, Witko (2007); Konisky, Woods (2012); \\
Produto Interno Bruto (PIB) & $\begin{array}{c}\text { Hays, Esler, Hays (1996); Daley, Garand (2005); Bueno (2013); Guan- } \\
\text { dalini (2016) } \\
\text { Despesa per capita }\end{array}$ \\
& Almeida (2010); Melo, Sousa (2016); Bueno (2013)
\end{tabular}

Desempenho Verde das Despesas Almeida (2010); Melo, Sousa (2016); Tridapalli et al. (2011)

Desempenho Ambiental do PIB Almeida (2010); Melo, Sousa (2016); Tridapalli et al. (2011)

Gasto Ambiental por Área

Potoski e Woods (2012), Newmark, Witko (2007); Almeida (2010); Melo, Sousa (2016);

Gasto Ambiental por Habitante Almeida (2010); Melo, Sousa (2016); Tridapalli et al. (2011)

Densidade Demográfica

Stanton, Whitehead, (1994); Lombard (1993); Daley, Garand (2005); Melo, Sousa (2016); Bueno (2013); Guandalini (2016)

Fonte: Dados da pesquisa.

O estudo de Magnani (2000) concluiu que, nesses países, o PIB per capita apresentou uma robusta significância estatística com os gastos ambientais estudados, ou seja, quanto maior o PIB per capita maior o gasto e, na sua contrapartida, quanto menor a desigualdade na distribuição da renda (Índice de GINI) maiores são os gastos públicos com pesquisa e desenvolvimento para a área ambiental.

Já o estudo conduzido por Daley e Garand (2005) não obteve resultados conclusivos, além de evidenciar a existência de problemas de colinearidade. Apesar disto, os autores relatam entre as variáveis determinantes da política estatal de lixo perigoso (variável dependente) existem fatores que estão correlacionados, entre elas estão as variáveis socioeconômicas (PIB industrial per capita, educação e densidade demográfica).

Bueno (2013) buscou analisar os fatores associados ao comportamento dos gastos ambientais nos municípios do Paraná no período de 2002 a 2011. Os resultados indicaram que houve um crescimento no volume de gastos ambientais nos municípios, além do crescimento na estrutura ambiental local. Outra conclusão foi a de que características socioeconômicas exercem grande influência sobre os gastos ambientais nos municípios paranaenses. Contudo, a estrutura ambiental existente nesses municípios também apresentou significância estatística.

Guandalini (2016) averiguou alguns determinantes dos gastos ambientais nos estados brasileiros, mensurando em que medidas diferentes as variáveis podem explicar a quantia gasta na função gestão ambiental dos estados para os anos de 2002 a 2012. Pela técnica de regressão múltipla, observou-se que questões socioeconômicas, político/sociais e ambientais realmente determinam os gastos ambientais. 
Para Konisky e Woods (2012), o pesquisador deve tomar cuidado na escolha tanto das técnicas quanto das variáveis a serem utilizadas no estudo, a fim de que este seja consistente. Quanto aos gastos públicos o estudo ratificou que estados com altos gastos ambientais per capita são normalmente pequenos, relativamente rurais e com baixo PIB e, de outra forma, estados com gastos ambientais totais mais elevados normalmente são maiores e com maiores níveis orçamentários, ou seja, utilizar gastos per capita ou totais pode fazer diferença em um determinado estudo e isso também deve ser analisado pelo pesquisador.

As pesquisas apresentadas utilizaram em sua grande maioria a técnica de regressão linear múltipla entre as variáveis dependentes e independentes, na qual, tais pesquisas buscavam estipular um conjunto de fatores que estivessem associados na determinação dessa dependência, sendo que algumas variáveis, mesmo sendo iguais nos diversos estudos, tiveram divergências, visto que em um estudo elas são significativas e em outros estudos não.

Com relação a isto, Bueno (2013) afirma que essas divergências não se devem somente a diferença na variável empregada para representar determinada teoria, mas também ao uso de valores absolutos, relativo e per capita, sendo que, cada autor deve especificar a unidade que melhor se adapta ao seu estudo.

\section{METODOLOGIA}

De acordo com os objetivos propostos, este estudo pode ser classificado como descritivo e de abordagem quantitativa e longitudinal. É descritivo porque busca descrever os fatores associados ao gasto público ambiental municipal. (COLLIS; HUSSEY, 2005; GIL, 1999; VERGARA, 2005).

No que concerne à abordagem do problema, a pesquisa é quantitativa, ou seja, a pesquisa envolverá os processos de coleta, análise e interpretação de dados numéricos e aplicação de testes estatísticos e, suas relações com fenômenos de atuação prática, e que proporcionam elementos sobre as características de um determinado problema ou questão. É um estudo longitudinal devido a utilização de uma ou mais variáveis, para analisar a dinâmica de uma situação durante um longo período de tempo (CRESWELL, 2010).

A coleta de dados ocorreu por meio de relatórios de execução orçamentária com as informações das Despesas Pagas por Função dos dados individuais dos 303 municípios brasileiros com mais de 100 mil habitantes (IBGE, 2016), no período compreendido de 2005 a 2015, disponíveis no sítio da Secretaria do Tesouro Nacional (STN), na qual foram corrigidos pelo Índice Geral de Preços - Disponibilidade Interna (IGP-DI), que é empregado contratualmente para correção de determinados preços administrados. De acordo o Banco Central do Brasil (BCB, 2016), no longo prazo, os valores do o Índice Nacional de Preços ao Consumidor Amplo -IPCA (índice oficial usado pelo governo federal para política monetária e fiscal) e do IGP - DI convergem para valores similares (BCB, 2016). Outros dados foram coletados no sítio do IBGE).

A função orçamentária que correspondente aos gastos ambientais foi classificada com o código 18 (FINBRA - Secretária do Tesouro Nacional), e essa classificação permite uma análise mais detalhada sobre o gasto ambiental, uma vez que permite a sua classificação nas seguintes subfunções: Preservação e Conservação Ambiental; Controle Ambiental; Recuperação de Áreas Degradadas; Recursos Hídricos; Meteorologia.

O gasto público ambiental municipal anual, que consiste na contabilização de cada município na função Gestão Ambiental (18) executado do orçamento municipal, por ser a principal variável, será considerada como a variável dependente, sendo que as outras variáveis serão tachadas como variáveis independentes, conforme apresentadas a seguir na tabela 2. 
Tabela 2 - Variáveis consideradas na pesquisa.

\begin{tabular}{|c|c|c|}
\hline Variável & Período & Autores \\
\hline \multicolumn{3}{|r|}{ Variável Dependente } \\
\hline Gasto Ambiental & $2005-2015$ & $\begin{array}{l}\text { Sacco, Leduc (1969); Stanton, Whitehead (1994); Lombard, } \\
\text { (1993); Potoski, Woods, (2012); Newmark, Witko (2007); Konisky, } \\
\text { Woods (2012); Bacot, Dawes (1997); Bueno (2013); Guandalini } \\
\text { (2016) }\end{array}$ \\
\hline \multicolumn{3}{|r|}{ Variáveis Independentes } \\
\hline Despesa Geral & $2005-2015$ & $\begin{array}{l}\text { Lombard (1993); Sacco, Leduc (1969); Bueno (2013); Guandalini } \\
\text { (2016) }\end{array}$ \\
\hline Renda per capita & $2005-2014$ & $\begin{array}{l}\text { Sacco e Leduc (1969), Stanton, Whitehead (1994), Lombard } \\
\text { (1993); Newmark, Witko, (2007); Konisky, Woods (2012); Hays, } \\
\text { Esler, Hays (1996); Daley, Garand, (2005); Bueno (2013) }\end{array}$ \\
\hline $\begin{array}{c}\text { Produto Interno Bru- } \\
\text { to (PIB) }\end{array}$ & $2005-2014$ & $\begin{array}{l}\text { Sacco, Leduc (1969); Stanton, Whitehead (1994); Lombard } \\
\text { (1993); Magnani (2000); Newmark, Witko (2007); Konisky, Woods } \\
\text { (2012); Hays, Esler, Hays (1996); Daley, Garand (2005); Bueno } \\
\text { (2013); Guandalini (2016) }\end{array}$ \\
\hline Despesa per capita & $2005-2015$ & Almeida (2010); Melo, Sousa (2016); Bueno (2013) \\
\hline $\begin{array}{l}\text { Desempenho Verde } \\
\text { das Despesas }\end{array}$ & $2005-2015$ & Almeida (2010); Melo, Sousa (2016); Tridapalli et al. (2010) \\
\hline $\begin{array}{l}\text { Desempenho Am- } \\
\text { biental do PIB }\end{array}$ & $2005-2014$ & Almeida (2010); Melo, Sousa (2016); Tridapalli et al. (2010) \\
\hline $\begin{array}{l}\text { Gasto Ambiental por } \\
\text { Área }\end{array}$ & $2005-2015$ & $\begin{array}{l}\text { Potoski e Woods (2012), Newmark, Witko (2007); Almeida (2010); } \\
\text { Melo, Sousa (2016); }\end{array}$ \\
\hline $\begin{array}{l}\text { Gasto Ambiental por } \\
\text { Habitante }\end{array}$ & $2005-2015$ & Almeida (2010); Melo, Sousa (2016); Tridapalli et al. (2010) \\
\hline $\begin{array}{l}\text { Densidade Demo- } \\
\text { gráfica }\end{array}$ & $2005-2015$ & $\begin{array}{l}\text { Stanton, Whitehead, (1994); Lombard (1993); Daley, Garand } \\
\text { (2005); Melo, Sousa (2016); Bueno (2013); Guandalini (2016) }\end{array}$ \\
\hline
\end{tabular}

A variável "despesa Geral", representa a soma de todas as despesas anuais dos municípios, ou seja, é a soma de todas as funções (despesas orçamentárias empenhadas). De acordo com os autores citados (ver tabela 2), a despesa geral normalmente possui relação positiva como gasto ambiental; a renda per capita, representa a divisão do índice de riqueza municipal pelo número de habitantes pelo número de habitantes de cada estado; o Produto Interno Bruto (PIB) foi coletado a preços correntes (em mil reais). Sendo assim, a Renda per capita e o PIB espera uma relação positiva com a variável dependente, ou seja, quanto maior o poder aquisitivo de uma população, maior riqueza econômica e maior será o gasto com o meio ambiente.

Quanto às variáveis despesa per capita, desempenho verde das despesas, desempenho ambiental do PIB, gasto ambiental por área e gasto ambiental por habitante, criados por Almeida (2010), estes são indicadores de desempenho ambiental para o setor público. Relacionam os gastos ambientais fixados decorrentes do orçamento com os componentes despesa orçamentária total, buscando analisar o quanto é investido e gasto na gestão ambiental em decorrência das despesas fixadas. Outros componentes utilizados para a correlação com os gastos ambientais foram: a área total do município, o PIB e o número de habitantes. Deste modo, os indicadores identificam o desempenho verde de cada entidade de natureza pública.

A despesa per capita é a soma de todos os gastos orçamentário dos municípios divididos pelo número de sua população.

O desempenho verde das despesas, sintetiza os resultados obtidos a partir da relação quociente dos valores referentes às despesas totais e os gastos em gestão ambiental nas prefeituras pesquisadas (código 18); desempenho ambiental do PIB, é a relação do PIB dos municípios 
pesquisados com os seus gastos realizados em gestão ambiental. Espera-se uma relação direta entre essas variáveis, à medida que aumenta os gastos totais do município, ocorra um aumento nas despesas com gestão ambiental.

O gasto ambiental por área territorial e o gasto ambiental por habitante, que representa, respectivamente, o total gasto com gestão ambiental, em relação à extensão dos municípios e o quanto tem sido investido em meio ambiente por cada morador da cidade. Já a densidade demográfica é a razão entre a população e a área de desse território, permitindo verificar a intensidade de ocupação do município. Deste modo, a relação esperada é a de que quanto maiores esses valores, maiores sejam os gastos ambientais municipais.

Então, nesse estudo, empregou-se a análise de regressão linear múltipla, com os dados dos gastos públicos com meio ambiente, bem como dos dados socioeconômicos dos municípios analisados. Segundo Gujarati e Porter (2011, p. 39), análise de regressão é o estudo "[...] da dependência de uma variável, a variável dependente, em relação a uma ou a mais variáveis, as variáveis explanatórias, com vistas a estimar e/ou prever o valor médio (da população) da primeira em termos dos valores conhecidos ou fixados (em amostragens repetidas) das segundas".

O modelo de regressão linear múltipla pode ser obtido por (1):

$$
Y=\alpha+\beta_{1} X_{1}+\beta_{2} X_{2}+\cdots+\beta_{k} X_{k}+\mu
$$

Onde:

$Y=$ representa o fenômeno em estudo (variável dependente);

$\alpha=$ coeficiente linear, constante ou intercepto, evidencia o ponto na reta de regressão no qual $X=0$ (intercepto);

$\beta_{k}=$ coeficiente de cada variável (coeficientes angulares de incremento ou decremento) e indica a inclinação da reta, ou seja, quanto $Y$ varia para cada unidade adicional de cada $X$ incluído no modelo;

$x_{k}=$ variáveis independentes (variáveis explicativas - métricas ou dummies);

$\mu=$ termo de erro, captura o efeito das variáveis não incluídas no modelo.

Por meio da regressão múltipla a variância de $Y$ (variável dependente) é explicada pelo comportamento de variação da variável $X$ (variáveis independentes). Esta capacidade é chamada de poder explicativo da regressão e é medida pelo coeficiente de ajuste ou de explicação $R^{2}$. Fávero (2015) e Gujarati e Porter (2011) definem $\mathrm{R}^{2}$ como a fração da variância da amostra de $Y$ explicada (ou prevista) pelas variáveis explicativas, ou seja, como a proporção da variação amostral da variável dependente explicada pelo conjunto de variáveis explicativas, que serve de medida para o grau de ajuste do modelo proposto.

Para avaliação da significância geral do modelo e de cada um dos parâmetros tirou-se proveito da aplicação do teste $F$ e o teste $t$ ( $p$-value). Segundo Fávero $(2015$, p. 20$)$ o teste $F$ possibilita "[...] verificar se o modelo que está estimado de fato existe, uma vez que, se todos os $\beta$ j forem iguais a zero, o comportamento de alteração de cada uma das variáveis explicativas não influenciará em absolutamente nada o comportamento de variação da variável dependente".

Dessa maneira, é preciso que se "[...] avalie se cada um dos parâmetros do modelo de regressão é estatisticamente diferente de zero, a fim que de a sua respectiva variável $X$ seja, de fato, incluída no modelo final proposto". Nesse sentido, a estatística $t$ é importante, pois fornece ao pesquisador "[...] a significância estatística de cada parâmetro a ser considerado no modelo de regressão [...]" (FÁVERO, 2015, p. 22). 
A diretriz normalmente utilizada é a de que para um nível de confiança de $95 \%$ os valores de significância de $F$ e $t$ ( $p$-value) devem ser inferiores a 0,05 (FÁVERO et al.; 2009).

Por fim, com as informações extraídas das bases secundárias, para análise que envolve estatística descritiva empregou-se um editor de planilhas eletrônico e, para a análise multivariada, utilizou-se um software estatístico para análise e manipulação de dados.

O emprego da regressão linear múltipla como técnica de análise, proporciona tanto a confirmação sobre a robustez do modelo testado quanto a elaboração de inferências, ou mais especificamente, a predição dos possíveis valores para o gasto ambiental municipal.

Estimou-se, inicialmente, o modelo de regressão via Mínimos Quadrados Ordinários (MQO ou em inglês, Ordinary Least Squares - OLS). No entanto, foram encontrados problemas causados pela presença de heterocedasticidade. Para melhorar a qualidade da estimação dos parâmetros do modelo, posteriormente, as regressões foram realizadas via Mínimos Quadrados Generalizados (MQG) devido à necessidade de minimizar a variância dos estimadores, tornando -os mais consistentes e confiáveis (Gujarati e Porter, 2011).

Para que exista maior inferência sobre os resultados gerados pela regressão múltipla, Gujarati e Porter (2011) argumentam que um modelo geral, estimado pelo método dos mínimos quadrados ordinários (MQO), possui algumas premissas básicas que devem ser consideradas. Dentre elas é comum encontrar, em pesquisas em que empresas com características diferentes são os objetos de estudos, problemas na estimação do modelo devido à ausência de homocedasticidade. Nesse caso, a estimação de MQO deve ser tratada de forma especial, uma vez que encontre realmente a presença de heterocedasticidade ou heterogeneidade dos resíduos.

Para Wooldridge (2017), um método alternativo à correção de White é a heterocedasticidade corrigida, que calcula uma série ponderada dos resíduos (quando há um número elevado de variáveis explicativas no modelo, pois a inclusão de todos os termos e combinações, formulados para o teste, pode consumir rapidamente os graus de liberdade). Assim, a estimação dos parâmetros pode ser realizada por mínimos quadrados, desde que haja uma correção da matriz de covariância dos erros para considerar a heterocedasticidade. Em situações assim, a estimação, segundo Gujarati e Porter (2011) é dita robusta, e o método de estimação passa a ser denominado de mínimos quadrados generalizados (MQG, ou em inglês, generalized least square, ou apenas GLS).

\section{APRESENTAÇÃO E ANÁLISE DOS RESULTADOS}

Foi estimada a regressão linear múltipla pelo método mínimo quadrados generalizados para as 9 variáveis explicativas, a saber: Despesa Geral (DespG), Renda per capita (RendP), Produto Interno Bruto (PIB), Despesa per capita (DespP), Desempenho Verde das Despesas (DVD), Desempenho Ambiental do PIB (DAPIB), Gasto Ambiental por Área (GAA ${ }^{2}$ ), Gasto Ambiental por Habitante (GAH) e Densidade Demográfica (DM).

A análise por meio da regressão múltipla normalmente é iniciada pela inspeção na matriz de correlações. Assim, realizou-se o teste de correlação entre as variáveis explicativas, para observar se havia alguma correlação alta entre elas (Tabela 3).

Tabela 3 - Matriz de correlação linear das variáveis consideradas na pesquisa.

\begin{tabular}{cccccccccc}
\hline & DespG & RendP & PIB & DespP & DVD & DAPIB & GAA $^{2}$ & GAH & DM \\
\hline DespG & 1 & & & & & & & & \\
RendP & 0,0807 & 1 & & & & & & & \\
PIB & $-0,0532$ & 0,1294 & 1 & & & & & &
\end{tabular}




\begin{tabular}{cccccccccc} 
DespP & 0,1769 & 0,4362 & 0,1705 & 1 & & & & & \\
DVD & 0,0018 & 0,4936 & 0,0225 & 0,1037 & 1 & & & & \\
DAPIB & $-0,0059$ & $-0,0096$ & $-0,0094$ & 0,0053 & 0,1083 & 1 & & & \\
GAA $^{2}$ & 0,2361 & 0,2286 & 0,241 & 0,3277 & 0,2325 & 0,0742 & 1 & & \\
GAH & 0,0418 & 0,4592 & 0,0575 & 0,4386 & 0,613 & 0,151 & 0,5226 & 1 & \\
DM & 0,2457 & 0,0283 & 0,2749 & 0,0006 & $-0,0345$ & $-0,0168$ & 0,3243 & $-0,0304$ & 1 \\
\hline
\end{tabular}

Fonte: Dados da pesquisa.

Verificando a Tabela 1 é possível verificar que as variáveis selecionadas não possuem altos níveis de correlação entre as variáveis explicativas, sugerindo então ser um bom grupo de variáveis selecionadas para o modelo. De acordo Hair et al (2005) se os valores apresentados na matriz de correlação (em módulo) forem inferiores a 0,7 serão considerados com correlação moderada, para valores abaixo de 0,4 são avaliados como pequenos, e, menores que 0,2 , como leves.

Observa-se inicialmente que a correlação dos componentes socioeconômicos do trabaIho, corrobora com a revisão empírica realizada com os diversos estudos sobre gastos ambientais (LOMBARD, 1993; STANTON; WHITEHEAD, 1994; BACOT; DAWES, 1997; DALEY; GARAND, 2005; NEWMARK; WITKO, 2007; SOUZA et al., 2012; BUENO, 2013; GUANDALINI, 2016), nos quais, Despesa Geral, Renda per capita, Produto Interno Bruto, Despesa per capita e Densidade Demográfica normalmente são variáveis analisadas como fatores com poder explicativo sobre os gastos ambientais.

A equação resultante do ajuste do modelo é a seguinte (2):

$$
Y=\alpha+\beta_{1} X_{1}+\beta_{2} X_{2}+\beta_{3} X_{3}+\beta_{4} X_{4}+\beta_{5} X_{5}+\beta_{6} X_{6}+\beta_{7} X_{7}+\beta_{8} X_{9}+\beta_{9} X_{9}
$$

Onde:

$Y=$ valor do gasto público ambiental dos municípios brasileiros;

$\alpha=$ coeficiente linear 0 (intercepto);

$\beta_{1} x_{1}=$ variável Despesa Geral (\$);

$\beta_{2} X_{2}=$ variável Renda per capita (\$);

$\beta_{3} X_{3}=$ variável Produto Interno Bruto - PIB (\$);

$\beta_{4} X_{4}=$ variável Despesa per capita $(\$) ;$

$\beta_{5} X_{5}=$ variável Desempenho Verde das Despesas (\%);

$\beta_{6} X_{6}=$ variável Desempenho Ambiental do PIB (\%);

$\beta_{7} X_{7}=$ variável Gasto Ambiental por Área $\left(\$ / \mathrm{Km}^{2}\right)$;

$\beta_{8} X_{3}=$ variável Gasto Ambiental por Habitante (\$);

$\beta_{9} X_{9}=$ variável Densidade Demográfica $\left(\right.$ hab $/ \mathrm{Km}^{2}$ ).

De acordo com os dados necessários à qualidade do ajustamento do modelo, exibidos na Tabela 2, com base na interpretação dos gastos públicos ambientais municipais da amostra, com intervalo de $95 \%$ de confiança, observa-se que, pelo teste de distribuição $F$, os modelos estão bem ajustados.

Tabela 2 - Especificações da variação da variável "Gasto Ambiental" explicada pelo modelo de regressão linear (com intervalo de confiança de 95\%).

\begin{tabular}{ccccccc}
\hline $\begin{array}{c}\text { Número de ob- } \\
\text { servações }\end{array}$ & $\begin{array}{c}\text { Graus de liber- } \\
\text { dade }\end{array}$ & $F$ & Prob> F & $\mathbf{R}^{\mathbf{2}}$ & $\begin{array}{c}\text { Raízes dos Erros Qua- } \\
\text { dráticos Médios }\end{array}$ \\
$\mathrm{Y}$ & 2.722 & 9 & 113,37 & 0,0000 & 0,8582 & $1,0 \times 10^{7}$ \\
\hline
\end{tabular}

Fonte: Dados da pesquisa. 
Conforme demonstrado também na Tabela 1, rejeitou-se a hipótese nula, uma vez que o nível de significância $F$, para $95 \%$ de confiança, se apresentou abaixo de 0,05 , o que levou à aceitação da hipótese alternativa, na qual pelo menos uma das variáveis é significativa. O coeficiente de determinação $\left(R^{2}\right)$ do modelo sugere que $85,82 \%$ da variação do gasto público ambiental dos municípios brasileiros é explicada pelas variáveis selecionadas. O restante da variação, 14,18\%, é atribuído a fatores não incluídos no estudo.

Diante disso, também com um intervalo de confiança de 95\%, a Tabela 3 apresenta para a análise os resultados para interpretação dos valores estimados dos parâmetros.

Tabela 3 - Resultado dos valores estimados para os parâmetros do modelo de regressão linear da variável "Gasto Ambiental" (com intervalo de confiança de 95\%).

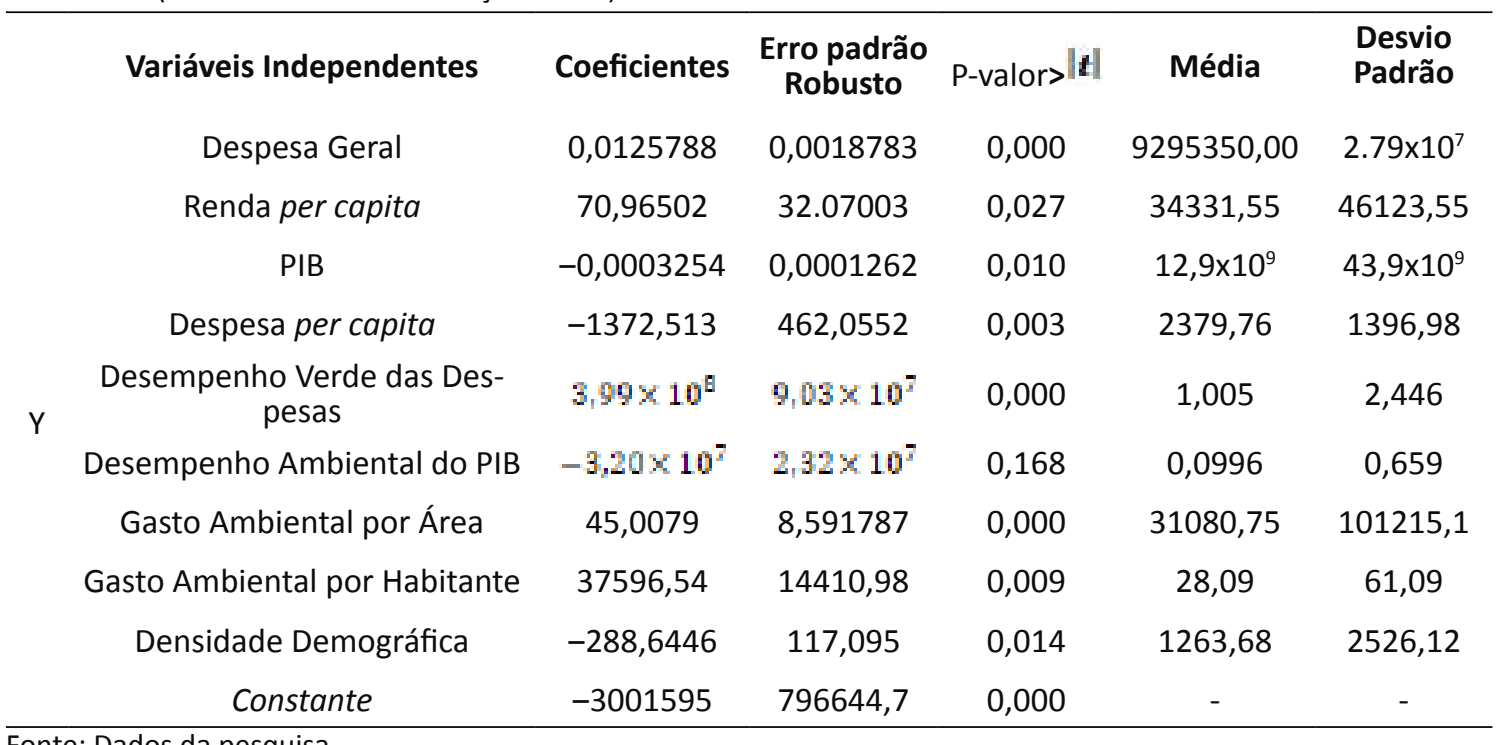

De acordo com Hair et al. (2005), o P-valor representa o menor nível de significância para rejeitar uma hipótese nula, sendo que o nível de significância é a probabilidade de rejeitar Ho quando Ho é verdadeira. Ho (hipótese nula) não existe relacionamento significativo nas diferenças entre as variáveis e Ha (hipótese alternativa) existe um relacionamento significativo.

$\mathrm{Na}$ análise geral, observando o P-valor, demonstrou-se que as variáveis Despesa Geral, Renda per capita, Produto Interno Bruto, Despesa per capita, Desempenho Verde das Despesas, Gasto Ambiental por Área, Gasto Ambiental por Habitante, Densidade Demográfica e a Constant apresentaram influência significativa sobre a variável dependente Gasto Público Ambiental. 0 Desempenho Ambiental do PIB, que é a participação dos gastos ambientais na riqueza municipal, foi a única variável do modelo (Tabela 3) que não demonstrou significância para os gastos públicos ambientais municipais, entre 2005 e 2015.

Considerando a variável Despesa Geral, para cada aumento de uma unidade monetária nas despesas orçamentárias municipais, o aumento nas despesas com meio ambiente tem um financeiro impacto maior.

Bueno (2013) e Guandaline (2016) em suas pesquisas concluem que a variável Despesas ou Gasto Geral está fortemente relacionada ao gasto ambiental. Segundo os autores, as regiões que possuem maior PIB e despesa total são os mais envolvidos com atividade de gestão ambiental

Em relação à Renda per capita destes municípios, os resultados mostraram uma relação positiva, quanto maior o valor dessa variável nos municípios, maiores são as despesas públicas ambientais. 
Stanton e Whitehead (1994) em seu estudo, estimaram que a renda per capita foi o único fator associado a duas variáveis dependentes: gastos ambientais destinados a qualidade do ar e da água. Considerando os gastos ambientais, a variável renda per capita, indica o forte poder explicativo de variáveis econômicas.

Apesar de ter utilizado em sua amostra somente países com alto nível de renda per capita, o estudo de Magnani (2000) concluiu que a Renda per capita apresentou uma robusta significância estatística com os gastos ambientais estudados, ou seja, quanto maior a Renda per capita maior o gasto ambiental.

Outra variável que teve uma relação positiva com o gasto ambiental foi o Desempenho Verde das Despesas, que consiste na participação do gasto em gestão ambiental nas despesas orçamentárias dos municípios. Os resultados mostram uma correlação direta dessa variável com o volume de gasto ambiental municipal, ou seja, os municípios estão ampliando a participação da gestão ambiental nos municípios.

O estudo de Melo e Sousa (2016), contrapôs este resultado para a mesma variável Desempenho Verde das Despesa, a referida variável dispôs de uma relação negativa com o gasto ambiental nos municípios (no estado da Paraíba) pesquisados, sinalizando que os gestores não estão adotando uma política de governo priorizando ações voltadas ao meio ambiente.

Outra relação positiva foi estabelecida entre gasto ambiental por área e por habitante. Quando ocorre o aumento em unidades monetárias do gasto ambiental tanto por área como por habitante, parte dessa despesa está associada ao aumento do gasto ambiental do município.

Para Bacot e Dawes (1997) a população é um fator associado ao gasto ambiental, pois quanto maior a população, maior a demanda por políticas ambientais, incluindo a legislação e os fundos necessários a execução dos programas.

Bueno (2013), em sua pesquisa, corrobora com esta afirmação, pois no estudo nos municípios paranaenses, a população e a área municipal é significativa perante o gasto ambiental, possuindo também uma relação positiva.

Pela tabela 4, também é possível identificar variáveis que tiveram comportamento negativo em relação a variável dependente (PIB, Densidade Demográfica, Despesa per capita e Densidade Demográfica)

Com relação ao PIB dos municípios pesquisados, os resultados constataram uma relação negativa, quanto maior o valor desta variável, menores são os gastos com o meio ambiente nestes municípios.

No estudo de Sacco e Leduc (1969), também confirmou o resultado apresentado anteriormente, demostrando a mesma relação negativa com a variável gasto ambiental. Essa relação pode estar relacionada com a seguinte situação: à medida que o PIB municipal cresce, maior será o valor gasto com a gestão ambiental nos municípios, mas o valor adicional que se despende em meio ambiente nessas localidades pode não ser ao proporcional ao ritmo de crescimento da riqueza econômica. Por outro lado, nos estudos de Newmark e Witko (2007) e Konisky e Woods (2012), a variável que mede o Índice de Riqueza Econômica, que no caso brasileiro é o PIB, a relação com a variável gasto público ambiental, foi significativa, porém, influenciando positivamente os gastos ambientais.

Sobre essa diferença de resultados em diferentes lugares, alguns autores afirmam que a influência da riqueza econômica (PIB) sobre o meio ambiente depende fortemente da disponibilidade financeira em se gastar mais com o meio ambiente, e o perfil das pessoas com maior renda ser mais suscetível a apoiar políticas ambientais mais consistentes. Portanto, as diferenças regionais e o contexto socioeconômico vão ser capazes de influenciar o gasto ambiental (SACCO; LEDUC, 1969; STANTON; WHITEHEAD, 1994; NEWMARK; WITKO, 2007; KONISKY; WOODS, 2012; DALEY; GARAND, 2005).

Quanto à variável Despesa per capita, há uma relação inversa com relação aos gastos ambientais, apresentando um valor negativo. $O$ resultado reforça as conclusões estimadas por Melo 
e Sousa (2016), que constataram o mesmo tipo de comportamento para a despesa per capita. Os autores frisam que os municípios ainda não demonstram um planejamento de ações e programas voltados ao meio ambiente regional, pois os gastos públicos nos municípios analisados representam valores relativamente baixos se comparadas às despesas totais/número de habitantes.

Outra relação negativa foi com a variável Densidade Demográfica, em que se aumentando o número de pessoas por quilômetro quadrado, ocorre uma redução do gasto ambiental. Diferentemente, Sacco e Leduc (1969) encontraram que a densidade demográfica, influencia positivamente o gasto ambiental. Os primeiros resultados da pesquisa dos autores supracitados, revelaram que o grau de urbanização (densidade populacional) influenciava os gastos ambientais, isto é, estados mais urbanizados gastavam mais com controle da poluição do ar e controle da qualidade da água.

Paiva e Wajnmam (2005) avaliaram ainda que, apesar do crescimento populacional da área urbana poder colaborar para o crescimento econômico, ele intrinsecamente não traz garantia na melhoria da distribuição de renda; pelo inverso, a expansão populacional pode ocasionar uma maior desigualdade social, menores níveis de desenvolvimento humano e a ampliação da pobreza. Nesse sentido, com uma maior densidade demográfica, e consequentemente, maiores problemas urbanos, gastos maiores em meio ambiente podem ser a resposta.

Já as variáveis Produto Interno Bruto, Despesa per capita e Densidade Demográfica obtiveram sinal negativo para os gastos ambientais, contrariando, em partes, a teoria. Mesmo assim, a partir dos resultados dos estudos citados anteriormente, confirmam que fatores atrelados ao meio ambiente, tais como os testados na pesquisa, podem interferir no desempenho das políticas ambientais.

Por fim, quando se discute numa tendência mais ambientalista, outras características da influência da riqueza econômica sobre o meio ambiente podem ser consideradas. A atenção, nesse tipo de vertente, volta-se principalmente ao próprio andamento da economia, em que estão atados dois fatores principais: a produção e o consumo, que afetam diretamente o meio ambiente (SCHNAIBERG, 1997; FOLADORI, 1999).

\section{CONSIDERAÇÕES FINAIS}

A descentralização de políticas públicas, o desenvolvimento sustentável e a gestão ambiental são questões presentes no debate atual sobre políticas públicas voltadas ao meio ambiente. $O$ desenvolvimento socioeconômico da humanidade, associado às preocupações com os impactos da produção econômica e seis impactos ambientais, interferindo na qualidade de vida das futuras gerações, além do processo de descentralização das ações públicas no Brasil, tornaram fundamental e inevitável a prática de políticas públicas ambientais. Assim, esta passa a ser de grande interesse para a sociedade, empresas e, principalmente, para os governos.

Nesse sentido, surgem cada vez mais estudos que se empenham em analisar todo o processo dos gastos públicos em meio ambiente, e, como estes recursos interferem nas políticas públicas voltadas ao meio ambiente. Neste contexto, há uma crescente evolução das pesquisas que visam identificar se existem fatores que influenciam e/ou determinam esses gastos públicos.

O presente trabalho objetivou investigar a existência de variáveis socioeconômicas e ambientais associadas ao comportamento dos gastos públicos com a função gestão ambiental no orçamento de municípios brasileiros com população igual ou superior a 100 mil habitantes, no período 2005 a 2015.

Observou-se, a partir da literatura pesquisada, que as questões socioeconômicas e ambientais influenciam os gastos ambientais municipais. Para confirmar essa relação, foi realizada uma análise de regressão, utilizando variáveis que contemplem dimensões socioeconômicas e ambientais, para explicar o comportamento dos gastos relativos à função ambiental dos municípios. 
Com base nas variáveis selecionadas, os resultados indicaram a significância de 8 variáveis explicativas: Despesa Geral, Renda per capita, Produto Interno Bruto, Despesa per capita, Desempenho Verde das Despesas, Gasto Ambiental por Área, Gasto Ambiental por Habitante e Densidade Demográfica. Essas variáveis selecionadas, sinalizaram um poder explicativo de $85,82 \%$ sobre os gastos ambientais realizados pelos municípios brasileiros no período estudado.

$\mathrm{O}$ acompanhamento dos gastos ambientais em pesquisas acadêmicas e no controle social das políticas ambientais pode ser um importante reforço para melhor caracterizar o empenho e demonstrar os fatores envolvidos na implementação das políticas ambientais; contribuindo e ampliando a área de conhecimento que trata da gestão ambiental no setor público.

A pesquisa realizada apresentou algumas limitações no que concerne a seleção das variáveis. Na literatura, outras variáveis são utilizadas para avaliar os fatores associados ao gasto público ambiental. Outra limitação diz respeito a restrições quanto aos valores informados pelas prefeituras municipais, uma vez em que houve situações em que os gestores municipais informaram que o gasto ambiental foi igual a zero.

Como proposta para novas pesquisas, sugere-se ampliar a coleta de dados para outras bases, como o Tribunal de Contas da União e Estados, levantar in loco informações sobre o gasto ambiental dos municípios que não disponibilizaram os dados e aplicar os questionários com gestores ligado à questão ambiental. Recomenda-se também, a inclusão, como dito anteriormente, de outras variáveis tais como: estrutura ambiental, questões políticas, sociais ideológicas e partidárias, grupos de interesse, entre outras.

Vários estudos já provaram a importância do Gasto Público Ambiental como um instrumento da política ambiental, principalmente no que tange aos determinantes, fatores associados e componentes que influenciam os gastos com meio ambiente. Os resultados apresentados talvez não sejam suficientes para explicar toda a dinâmica sobre o assunto. Contudo, não podem ser descartados, pois são dados importantes, principalmente no que tange ao âmbito nacional, e juntamente com outros, podem servem para a análise comparativa da política pública ambiental brasileira.

Estudar os gastos ambientais públicos é relevante, pois a informação disponibilizada pelas pesquisas permite acompanhar o desempenho das políticas ambientais implementadas pelo Estado. Uma abordagem para esse entendimento é realizar o acompanhamento da alocação desses recursos, por meio da identificação dos determinantes destes gastos.

Nesse sentido, este trabalho serve como mais uma contribuição relacionada ao tema, apresentando a importância dos gastos ambientais no contexto municipal, podendo ser uma ferramenta útil para gestores públicos municipais que possam auxiliar no planejamento da execução da política pública voltada ao meio ambiente.

\section{REFERENCIAS}

ALMEIDA, T.A.N. Evidenciação dos Gastos com Gestão Ambiental em Municípios Nordestinos no Período de 2005 à 2008. 2010. 125 f. Dissertação (Mestrado em Ciências Contábeis) - UnB/ UFPB/UFRN, João Pessoa, 2010.

ANDRADE, N. A. et. al. (Org.). Planejamento governamental para municípios: plano plurianual, lei de diretrizes orçamentárias e lei orçamentária anual. 2. ed. São Paulo: Atlas, 2008.

BACOT, A.H.; DAWES, R.A. State expenditures and policy outcomes in environmental program management. The Policy Studies Journal, v. 25, n. 3, p. 355-370, 1997. 
Gestão ambiental empresarial: conceitos, modelos e instrumentos. 3. ed. São Paulo: Saraiva, 2011, 376 p.

BCB, BANCO CENTRAL DO BRASIL. Índices de Preços no Brasil. Série Perguntas mais Frequentes (PMF 02). Diretoria de Política Econômica. Brasília, 2016. Disponível em: <https://www.bcb.gov. br/.../FAQ\%2002-Índices\%20de\%20Preços\%20no\%20Brasil.pdf. Acesso em abril de 2017.

BORINELLI, B.; TRIDAPALLI, J. P.; CAMPOS, M. F. S. S.; CASTRO, C. Gastos públicos em meio ambiente no Estado do Paraná: análise exploratória para o período 2002 a 2009. Revista de Políticas Públicas, v. 15, n. 1, jan./jun., 2011.

BUENO, W. Gasto público ambiental: uma análise dos municípios paranaenses no período de 2002 a 2011. 2013. 146 f. Dissertação (Mestrado em Administração) - Universidade Estadual de Londrina, Londrina, 2013.

CARneiRo, A. de F; MOURA, A. V. de. NETO, S. C. de G. Análise da Função de Despesa Gestão Ambiental nos Municípios de Rondônia. Revista de estudos contábeis, Londrina, v.4, n. 7, p. 7797, jul./dez. 2013

CARNEIRO, P. E. A. Modelo de mudanças climáticas com gastos públicos. Contexto Internacional, v. 30, p. 49-88, 2008. Disponível em: <https://goo.gl/EodsS1>. Acesso em: 04 abr. 2017.

COLLIS, J; HUSSEY, R. Pesquisa em administração: um guia prático para alunos de graduação e pós-graduação. 2 ed. Porto Alegre: Bookman, 2005, 352 p.

CRESWELL, J.W. Projeto de Pesquisa. Porto Alegre: Artmed, 2010, 296 p.

DALEY, D.M.; GARAND, J.C. Horizontal diffusion, vertical diffusion, and internal pressure in state environmental policymaking, 1989-1998. American Politics Research, v. 33 n. 5, p 615-644, set, 2005.

DANTAS, M.K.; PACHECO, L. M.; LIBONI; L. B.; CALDANA, A. C. F. Análise dos gastos públicos com gestão ambiental no brasil. RGSA - Revista de Gestão Social e Ambiental, São Paulo, v. 8, n.3, p. 52-68, set/nov. 2014.

DUTRA, R. C. D.; OLIVEIRA, A. B.; PRADO, A. C. A. Execução orçamentária do Ministério do Meio Ambiente entre 2000 e 2005. Revista Política Ambiental, Belo Horizonte, n. 2, set/2006.

FÁVERO, L. P. Análise de dados: Modelos de Regressão com Excel, Stata e SPSS. Rio de Janeiro: Elsevier, 2015.

FÁVERO, L. P.; BELFIORE, P.; SILVA, F. L.; CHAN, B. L. Análise de dados: modelagem multivariada para tomada de decisões. 4. reimp. Rio de Janeiro: Elsevier, 2009.

FOLADORI, G. Limites do desenvolvimento sustentável. Campinas: Unicamp, 2001.

GIACOMONI, J. Orçamento público. 13 ed. São Paulo: Atlas, 2007.

GIAMBIAGI, F.; ALÉM, A. C. D. Finanças Públicas: teoria e prática no Brasil. 2 ed. Rio de Janeiro: Elsevier, 2000.

GIL, A.C. Métodos e técnicas de pesquisa social. 5. ed. São Paulo: Atlas, 1999, 200 p.

GUANDALINI, N. N. Determinantes do gasto ambiental dos estados no Brasil: uma análise do período 2002-2012. 2016. 135 fls. Dissertação (Mestrado em Administração) - Universidade Estadual de Londrina, Londrina 2016. 
GUANDALINI, N. N; BORINELLI, B; GODOY, D. F. S. Gastos Públicos Ambientais nas Capitais dos Estados Brasileiros: Um Estudo Exploratório no Período de 2002 a 2010. UNOPAR Cient., Ciênc. Juríd. Empres, v. 14, n. 2, p. 207-216, set. 2013.

GUIMARÃES, P. C. V.; CARNEIRO, J. M. B.; DOWELL, S. M. Gasto na gestão ambiental no estado de São Paulo um estudo preliminar. RAP, v. 26, n. 2, p. 155-172, 1992.

GUJARATI, D. N.; PORTER, D. C. Econometria Básica. 5 ed. Porto Alegre: Bookman, 2011.

HAIR JR., J.F.; BABIN, B.; MONEY, A.H.; SAMOUEL, P. Fundamentos de métodos de pesquisa em administração.. Porto Alegre: Bookman, 2005.

HAYS, S.P.; ESLER, M.; HAYS, C. E. Environmental commitment among the states. Publius: The Journal of Federalism, v. 26: p. 41-58, 1996.

IBGE. Instituto Brasileiro de Geografia e Estatística. Despesas públicas por funções 1996-1998. IBGE: Rio de Janeiro, 2001, 456 p.

Estimativas da População Residente no Brasil e Unidades da Federação com Data de Referência em 10 de julho de 2016. 2016. Disponível em: <https://goo.gl/aMI6E5>. Acesso em: 04 abr. 2017.

KONISKY, D. M.; WOODS N. D. Measuring state environmental policy. Review of Policy Research, v. 29, n. 4, p. 544-569, 2012.

LEMOS, R. A. B.; YUONG, C. E. F.; GELUDA, L. Orçamento público para gestão ambiental: uma análise voltada para as áreas protegidas. In: III Simpósio de áreas protegidas. Universidade Católica de Pelotas/RS. Anais..., Pelotas, 2005.

LOMBARD, E.N. Determinants of state air-quality management: a comparative analysis. American Review of Public Administration, v. 23, p. 57-73, mar. 1993.

MAGNANI, E. The environmental Kuznets curve, environmental protection and income distribution. Ecological Economics, Sydney, v. 32, p. 431-443, ago. 1999.

MATIAS-PEREIRA, J. A governança corporativa aplicada no setor público. Administração Pública e Gestão Social, v.2, n. 1, p. 110-135, jan./ mar., 2010.

MELO, J.F.M.; SOUSA, A.F. Indicadores de desempenho ambiental no setor público: uma análise nos gastos ambientais e no desempenho verde de municípios. In: XVIII ENGEMA, 2016, São Paulo. Anais Eletrônicos...São Paulo, 2016. Disponível em: <https://goo.gl/s0Z4R3>. Acesso em: 04 abr. 2017.

NEWMARK, A.J; WITKO, C. Pollution, politics, and preferences for environmental spending in thestates. Review of Policy Research, v. 24, n. 4, p. 291-308, 2007.

NILES, M. T; LUBELL, M. Integrative frontiers in environmental policy theory and research. The Policy Studies Journal, v. 40, n. S1, p. 41-64, 2012.

PACHECO, L. M.; DANTAS, M. K.; PASSADOR, C. S.; AMUI; L. B. L. Gastos públicos ambientais: uma revisão integrativa da literatura e agenda para estudos futuros. In: XVII ENGEMA, 2015, São Paulo. Anais Eletrônicos...São Paulo, 2015. Disponível em: <https://goo.gl/NmyiKX>. Acesso em: 21 jul. 2017. 
PAIVA, P. T. A.; WAJNMAN, S. Das causas às consequências econômicas da transição demográfica no Brasil. Rev. Bra. Est. Pop., v. 22, n. 2. jul./dez. 2005.

POTOSKI, M.; WOODS, N. D. Dimensions of state environmental policies: air pollution regulation in the United States. Policy Studies Journal, v. 30, n. 2, p. 208-226, 2002.

SACCO, J. F.; LEDUC, E. C. An analysis of state pollution control expenditures. Journal of the Air Pollution Control Association, v. 19, p. 416-419, 1969.

SCARDUA, F.P. Governabilidade e descentralização da gestão ambiental no Brasil.2003. 234 f. Tese (Doutorado em Desenvolvimento Sustentável) - Universidade de Brasília, Brasília, 2003.

SCHNAIBERG, A. Sustainable development and the treadmill of production. In: BAKER, S. et al (Ed.). The politics of sustainable development: theory, policy and practice within the European Union. London \& New York: Routledge Press. 1997. Disponível em: <https://goo.gl/eda6Np>. Acesso em: 04 abr. 2017.

SECRETARIA DO TESOURO NACIONAL. Sistema de coleta de dados contábeis de Estados e Municípios - SISTN. Disponível em: www.stn.fazenda.gov.br/web/stn//consolidacao-das-contaspublicas---sistn-e-siconfi. Acesso em: 25 jan. 2017.

SILVA, R. A.; SILVA, E. P. de la S.; ADRIANO, N. de A.; Galazzi, G. A. A contabilidade governamental e os sistemas de informações gerenciais do governo federal brasileiro como instrumentos de controle social: a disponibilização das informações orçamentárias e financeiras pela internet. Revista Universo Contábil, v. 3, n 2, p. 73-86, maio./ago. 2007.

SOUSA, G. S. et al. Índice de qualidade ambiental: uma análise multivariada para os estados brasileiros. In: Encontro Nacional da Associação Brasileira de Estudos Regionais e Urbanos. Anais... Recife, 2012.

STANTON, T.; WHITEHEAD, J. C. Special interests and comparative state policy: analysis of environmental quality expenditures. Eastern Economic Journal, v. 20, n. 4, p. 441-452. 1994. Disponível em: https://www.jstor.org/stable/40325597. Acesso em: 15 mar. 2018

TRIDAPALLI, J.P. et al. Análise dos gastos ambientais no setor público brasileiro: características e propostas alternativas. Revista de Gestão Social e Ambiental - RVGSA, v.5, n.2, p.79-95, 2011.

WOOLDRIDGE, J. M. Introdução à econometria: uma abordagem moderna. 6. Ed. São Paulo: Cengage Learning, 2017

VERGARA, S. C. Métodos de Pesquisa em Administração. São Paulo: Atlas, 2005, 287 p.

YOUNG, C. E. F.; GELUDA, L.; LEMOS, R. Instrumento econômicos para o desenvolvimento sustentável: o caso brasileiro. In: PARREIRA. C; ALIMONDA, H (Org.). As instituições financeiras públicas e o meio ambiente no Brasil e na América Latina. Brasília: FLACSO-Brasil, 2006, p. 221-242.

YOUNG, C. E. F.; RONCISVALLE, C. A. Expenditures, investment and financing for sustainable development in Brazil. U.N. Comision Económica para América, Santiago, 2002. 